\title{
Article \\ Rumen Inoculum Enhances Cathode Performance in Single-Chamber Air-Cathode Microbial Fuel Cells
}

\author{
Ignacio T. Vargas $1,2, * \mathbb{1}$, Natalia Tapia ${ }^{1,2}$ and John M. Regan ${ }^{3}$ \\ 1 Department of Hydraulic and Environmental Engineering, Pontificia Universidad Católica de Chile, \\ Santiago 7820436, Chile; netapia@uc.cl \\ 2 Centro de Desarrollo Urbano Sustentable (CEDEUS), Santiago 7520246, Chile \\ 3 Department of Civil and Environmental Engineering, The Pennsylvania State University, \\ University Park, PA 16801, USA; jmr41@psu.edu \\ * Correspondence: itvargas@ing.puc.cl
}

Citation: Vargas, I.T.; Tapia, N.; Regan, J.M. Rumen Inoculum Enhances Cathode Performance in Single-Chamber Air-Cathode Microbial Fuel Cells. Materials 2022, 15, 379. https://doi.org/10.3390/ ma15010379

Academic Editors: Sneha Samal and Ignazio Blanco

Received: 21 November 2021

Accepted: 31 December 2021

Published: 5 January 2022

Publisher's Note: MDPI stays neutral with regard to jurisdictional claims in published maps and institutional affiliations.

Copyright: (c) 2022 by the authors. Licensee MDPI, Basel, Switzerland. This article is an open access article distributed under the terms and conditions of the Creative Commons Attribution (CC BY) license (https:// creativecommons.org/licenses/by/ $4.0 /)$.

\begin{abstract}
During the last decade, bioprospecting for electrochemically active bacteria has included the search for new sources of inoculum for microbial fuel cells (MFCs). However, concerning power and current production, a Geobacter-dominated mixed microbial community derived from a wastewater inoculum remains the standard. On the other hand, cathode performance is still one of the main limitations for MFCs, and the enrichment of a beneficial cathodic biofilm emerges as an alternative to increase its performance. Glucose-fed air-cathode reactors inoculated with a rumen-fluid enrichment and wastewater showed higher power densities and soluble chemical oxygen demand (sCOD) removal (Pmax $=824.5 \mathrm{mWm}^{-2} ; \Delta \mathrm{sCOD}=96.1 \%$ ) than reactors inoculated only with wastewater $\left(\operatorname{Pmax}=634.1 \mathrm{mWm}^{-2} ; \Delta \mathrm{sCOD}=91.7 \%\right)$. Identical anode but different cathode potentials suggest that differences in performance were due to the cathode. Pyrosequencing analysis showed no significant differences between the anodic community structures derived from both inocula but increased relative abundances of Azoarcus and Victivallis species in the cathodic rumen enrichment. Results suggest that this rarely used inoculum for single-chamber MFCs contributed to cathodic biofilm improvements with no anodic biofilm effects.
\end{abstract}

Keywords: microbial fuel cells; rumen fluid; cathodic biofilm

\section{Introduction}

Power densities achieved from microbial fuel cell (MFC) systems have increased by several orders of magnitude during the last decade. Before 2010, most of the reported results did not exceed $0.1 \mathrm{Wm}^{-2}$. However, in recent years, power densities greater than $1 \mathrm{Wm}^{-2}$ are more frequently found [1,2]. This rapid development has been primarily due to improvements in physical and chemical factors (e.g., architecture, electrode materials, membranes, and buffering) [1,3]. As these physicochemical considerations are addressed, opportunities emerge to enhance MFC performance through biological factors. Some of the current areas of microbial research in MFCs include exploring new sources of electrochemically active bacteria $(\mathrm{EAB})$ with distinct physiologies, characterizing complex community interactions, and understanding the electron transfer mechanisms that govern current generations [4,5].

Bioprospecting for $\mathrm{EAB}$ has been an important motivation for microbial research in MFCs. The search for new sources of EAB has included sludge from wastewater plants [6,7], sediments [8,9], rice paddy fields [10], forest soils [9,11], and rumen fluids [12-16]. Extreme environments have also been tested, taking inocula from salt marshes [17], saline microbial mats [9], salt lakes [18], tropical mangrove sediments [19], and acid mine drainage affected sites [20]. Bioprospecting studies have allowed the detection of a diversity of electrogenic microorganisms, which have been shown to generate high power densities when tested in pure cultures. However, some studies showed that mixed cultures have a better power 
performance [21,22]. This could be mainly due to the cooperation between different microorganisms, allowing for the decomposing of heterogeneous substrates or providing a beneficial environment for anaerobic EABs [23]. This enormous effort has focused on the effect of these new inoculum sources on the anodic microbial community and its performance, leaving less attention to the impact on the cathode.

The cathode is often the main limitation for power production, and the cost of platinized cathodes is prohibitive in large-scale applications. Hence, there has been considerable interest in developing alternative cathode materials such as activated carbon and electrochemically active cathodic biofilms to improve MFC performance. A single-chamber air-cathode MFC offers an efficient and scalable configuration [24]. However, this cathode configuration sustains the involuntary growth of a biofilm on the air-cathode that increases coulombic efficiency (CE) but decreases power production $[25,26]$. To address this limitation, the potential enrichment of a beneficial cathodic microbial community represents an alternative strategy to increase cathode performance in MFC systems.

Cow rumen fluid offers an opportunity to enrich diverse and unique microbial communities in MFC systems, with the potential of increasing substrate degradation efficiency and adding new EAB to enhance power production. The rumen of an adult dairy cow contains from $10^{9}$ to $10^{11}$ bacteria per liter of fluid and a virtually unknown microbial ecology. Nagaraja [27] estimated that less than $10 \%$ of the rumen microorganisms had been phylogenetically identified. The main function of this impressively rich microbiota is to digest plant polysaccharides and ferment the released sugars to produce volatile fatty acids, which are absorbed by the ruminant as a source of energy [27]. Both strict and facultative anaerobes have been observed as members of rumen consortia, and it is common to find syntrophic relationships in a ruminal biofilm, as bacteria that degrade intermediary metabolites produce a more efficient substrate utilization [14,27]. Previous MFC articles have reported on the use of rumen material as an inoculum. Rismani-Yazdi et al. [14] and Chung et al. [13] used H-type MFC reactors to demonstrate that rumen microorganisms can hydrolyze cellulose and produce electric energy.

Additionally, Rismani-Yazdi et al. observed that the addition of rumen inoculum to the anode chamber increased the microbial diversity. Using $16 \mathrm{~S}$ rRNA gene analysis, the authors identified Firmicutes as the dominant phylum in the anodic biofilm and Betaproteobacteria as the dominant phylum in the suspended culture. Different groups have used diverse MFC configurations with rumen inocula to demonstrate that it is possible to obtain electricity from an aquatic plant rich in cellulose, hemicellulose, and lignin [16,28-31]. Previous studies have also evaluated the effect of different catholytes on MFCs inoculated with rumen [12], the isolation of methanogens to increase power production in mixed community MFCs [15], and how the supplementation of dried red pepper modify the fermentation of rumen microorganism, thereby improving reactor performance [32]. Thus, previous studies have focused on anodic reactions and electricity production rather than quantifying how rumen ecology affects cathodic biofilm composition and the subsequent improvements on MFC performance. In this article, for the first time, cow rumen fluid was used to study the enrichment of both anodic and cathodic microbial communities in single-chamber air-cathode MFC reactors. Following microbial community analysis, the electrochemical performance of each biofilm and their effect on the overall power performance were quantified.

\section{Materials and Methods}

\subsection{MFC Construction and Operation}

Single-chamber air-cathode MFCs were constructed using cube-type plexiglass reactors of $28 \mathrm{~mL}$ volume. Graphite fiber brushes $2.5 \mathrm{~cm}$ in diameter and $2.5 \mathrm{~cm}$ long (PANEX 33 160K, ZOLTEK, Nyergesúffalu, Hungary) were placed horizontally in the cube reactors and used as anodes. Brushes were heat treated in a muffle furnace at $450{ }^{\circ} \mathrm{C}$ for $30 \mathrm{~min}$ [33]. Cathodes contained $0.5 \mathrm{mg} / \mathrm{cm}^{2}$ platinum catalyst applied to the water-facing side of 
carbon cloth (Type B-1B, E-TEK, $3.8 \mathrm{~cm}$ diameter, $7.1 \mathrm{~cm}^{2}$ of exposed surface area), and four polytetrafluoroethylene (PTFE) diffusion layers applied to the air-facing side [34].

MFCs were inoculated with effluent from a primary clarifier at The Pennsylvania State University Wastewater Treatment Plant (PSU-WWTP), a frequently used inoculum source for MFC reactors [2], and an enriched cow rumen sample. The rumen sample was collected from a cow at the dairy complex of The Pennsylvania State University and enriched for two weeks in a flask using $\mathrm{H}_{2(\mathrm{~g})}$ and fumarate as electron donor and acceptor, respectively. Under this condition, enrichment of lithotrophic bacteria capable of using fumarate as electron acceptor, such as Geobacter spp. [35], was expected.

Reactors were fed a medium containing $1 \mathrm{~g} / \mathrm{L}$ of glucose, $50 \mathrm{mM}$ phosphate buffer solution (PBS), and mineral $(12.5 \mathrm{~mL} / \mathrm{L})$ and vitamin $(5 \mathrm{~mL} / \mathrm{L})$ solutions [33]. Two conditions were tested in duplicate reactors: (1) MFCs inoculated with $14 \mathrm{~mL}$ of a mix (50:50 $v / v$ ) of enriched rumen fluid and wastewater (RU) and (2) MFCs inoculated using $14 \mathrm{~mL}$ of only wastewater $(\mathrm{WW})$. Since the rumen fluid was pre-enriched using fumarate as electron acceptor, two additional rumen reactors were, for each batch-cycle, amended with $60 \mathrm{mg} \mathrm{L}^{-1}$ of fumarate as an alternative electron acceptor.

MFCs were operated for 60 days as fed-batch reactors in a temperature-controlled room $\left(30 \pm 1{ }^{\circ} \mathrm{C}\right)$. Voltage was measured every $10 \mathrm{~min}$ across an external resistor of $1 \mathrm{k} \Omega$ using a data acquisition system (2700; Keithley, Cleveland, OH, USA). Batch cycles were 3 to 4 days, with the end of each cycle defined when voltage dropped below $20 \mathrm{mV}$ [36]. Current and power were normalized to the cathode projected surface area. Anode and cathode potentials were measured with a $7.5 \mathrm{~cm}$ long $\mathrm{Ag} / \mathrm{AgCl}$ reference electrode (MF2079, BASi, West Lafayette, IN, USA) inserted close to the cathode and the distal end of the brush anode. Power densities were calculated using the highest ten voltages for each batch cycle, and CE was calculated based on current produced and chemical oxygen demand (COD) consumed as previously described [34]. To obtain polarization data, the external resistance was varied from $10 \Omega$ to $40 \mathrm{k} \Omega$, allowing the systems to reach stable voltage at each resistance.

\subsection{Analyses}

Liquid samples were obtained from the MFCs at the end of each cycle, filtered with a syringe filter ( $0.2 \mu \mathrm{m}$ Supor Membrane, PALL Life Science, New York, NY, USA), and analyzed for soluble COD (sCOD) using the colorimetric method (Cat 21258-15; HACH, Loveland, CO, USA). Headspace gas samples $(250 \mu \mathrm{L})$ were collected in duplicate using a gas-tight syringe and analyzed by a gas chromatograph Model 8610 (SRI Instruments, Torrance, CA, USA) equipped with a thermal conductivity detector and a stainless-steel column $\left(1.8 \mathrm{~m} \times 1 / 8^{\prime \prime}\right)$ packed with Porapak Q (Alltech, Deerfield, IL, USA).

One of the duplicates of each condition was used for electrochemical analysis (as follows) the other reactors were saved for community analysis, avoiding possible effects of electrochemical tests on community structure. Potentiostatic electrochemical impedance spectroscopy (EIS) was performed on anodes and cathodes using a Reference 600 potentiostat (Gamry Instruments Inc., Warminster, PA, USA). MFCs were tested during the first $24 \mathrm{~h}$ of several cycles. Before each test, reactors were disconnected for $2 \mathrm{~h}$ to reach open circuit potential (OCP). A $7.5 \mathrm{~cm}$ long Ag/ AgCl electrode (MF-2079, BASi, West Lafayette, IN, USA) was used as reference; anode and cathode were used as working and counter electrodes. Anodic EIS was performed at OCP $(\sim 0.7 \mathrm{~V})$, with an AC potential of $10 \mathrm{mV}$ rms, frequencies from $10^{5}$ to $0.004 \mathrm{~Hz}$, at 10 points per decade of data acquisition [37]. Cathodic EIS was performed at DC potentials of $0.3 \mathrm{~V}, 0.1 \mathrm{~V}$, and $0.005 \mathrm{~V}$, with an AC potential of $10 \mathrm{mV} \mathrm{rms}$, frequencies from $10^{6}$ to $0.01 \mathrm{~Hz}$, at 10 points per decade of data acquisition. Impedance spectra were fitted with an equivalent circuit by $\chi^{2}$ minimization using the software Echem Analyst (Gamry Instrument Inc., Warminster, PA, USA).

Differences among power densities were evaluated with a one-way analysis of variance (ANOVA) and using Microsoft Excel data analysis (Microsoft 365, Version 2111, 2020r, Microsoft Corporation, Redmond, WA, USA). 


\subsection{Bacterial Community Analysis}

DNA from anodes and cathodes was, as according to previous MFC studies, extracted using a PowerSoil DNA Isolation Kit (MO BIO Laboratories, Carlsbad, CA, USA) [38]. Pyrosequencing analysis was performed using a Roche/454 Life Science Genome Sequencer [39] by amplification and sequencing of the 16S rRNA gene using the following bacterial primers: 27F (5'-AGAGTTTGATCMTGGCTCAG-3 $\left.{ }^{\prime}\right)$ and 907R (5'CCCCGTCAATTCMTTTGAGTTT-3'). The classification was against the manually curated SILVA gold aligned genes [40] using the Bayesian sequence classifier in the mother software package [41]. Classifications with differences of less than $0.5 \%$ were not reported.

\section{Results and Discussion}

\subsection{MFC Performance}

After 36 days of batch-cycle operation across an external resistance of $1 \mathrm{k} \Omega$, stable voltage profiles were observed for all tested reactors (Figure 1).

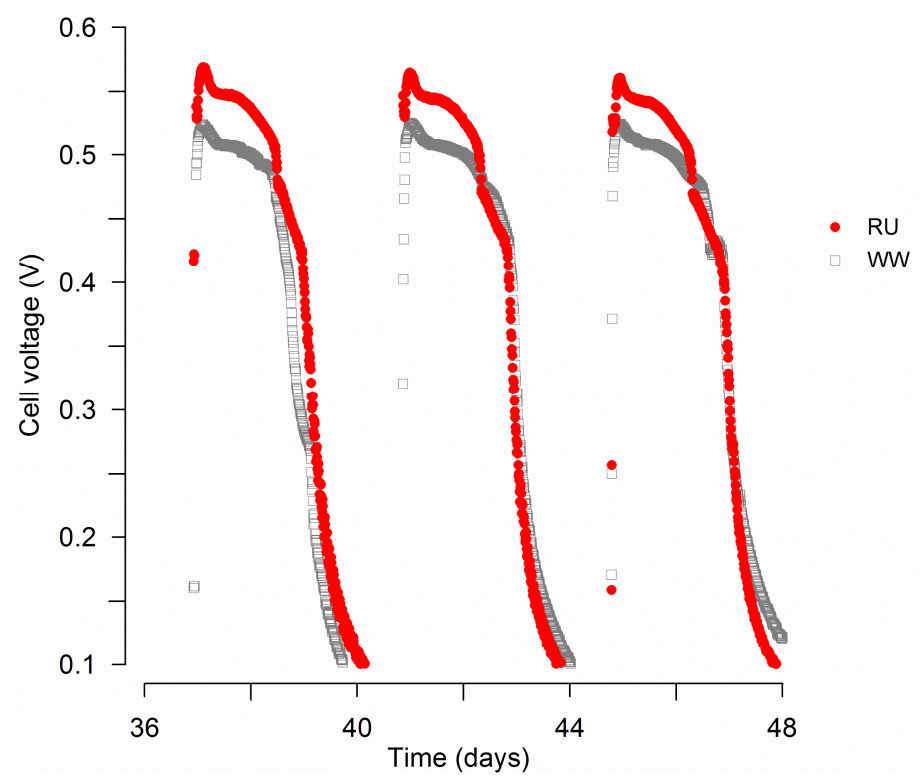

Figure 1. MFC reactors inoculated with a rumen enrichment showed higher cell voltages than reactors inoculated only with wastewater. RU: rumen plus wastewater; WW: wastewater. The figure shows the average results of duplicate reactors connected to external resistance of $1 \mathrm{k} \Omega$ over 3 batch cycles.

MFCs inoculated with rumen fluid and wastewater showed $20 \%$ higher operating power densities $\left(\mathrm{RU}=441 \pm 10 \mathrm{mWm}^{-2}\right.$ ) than those inoculated only with wastewater $\left(\mathrm{WW}=369 \pm 28 \mathrm{mWm}^{-2}\right)$. Headspace gas measurements at the end of three consecutive batch cycles after 40 days of operation did not reveal significant differences in gas composition. While hydrogen gas was not detected for any condition, methane and carbon dioxide percentages were very similar for both treatments (Table 1 ).

Table 1. Average performance observed during approximately 60 days of operation at $\mathrm{pH} 7,30^{\circ} \mathrm{C}$, and across $1 \mathrm{k} \Omega$ external resistance.

\begin{tabular}{ccccc}
\hline Reactor & $\begin{array}{c}\text { sCOD } \\
\text { Removal (\%) }\end{array}$ & $\begin{array}{c}\mathbf{C H}_{\mathbf{4}}{ }^{*} \\
\mathbf{( \% )}\end{array}$ & $\begin{array}{c}\mathrm{CO}_{\mathbf{2}}{ }^{*} \\
\mathbf{( \% )}\end{array}$ & $\begin{array}{c}\mathrm{CE} \\
\mathbf{( \% )}\end{array}$ \\
\hline Rumen plus WW (RU) & $96.1( \pm 0.5)$ & $14.9( \pm 1.3)$ & $7.1( \pm 1.4)$ & $22.8( \pm 0.9)$ \\
Wastewater (WW) & $91.7( \pm 4.1)$ & $14.4( \pm 2.1)$ & $5.9( \pm 1.4)$ & $23.0( \pm 0.4)$ \\
Rumen plus WW + & $95.6( \pm 0.2)$ & $12.3( \pm 1.1)$ & $5.8( \pm 0.6)$ & $22.3( \pm 1.1)$ \\
fumarate (RF) & & & & \\
\hline
\end{tabular}

* Values calculated as the average of 3 batch cycles after 40 days of operation. 
Maximum power densities determined from polarization tests were $824.5 \pm 30.8 \mathrm{mWm}^{-2}$ for RU and $634.1 \pm 56.4 \mathrm{mWm}^{-2}$ for $\mathrm{WW}$ reactors (Figure 2a). Statistical analysis of the three higher values in the power density curves (Figure 2a) shows a significant difference among RU and WW reactors. Polarization curves show that internal resistances were similar for both tested conditions: RU $=201 \Omega$ and $W W=200 \Omega$ (estimated as the slope of the lines in Figure $2 \mathrm{~b}$ over the current density range of 0.01 to $0.4 \mathrm{~mA} \mathrm{~cm}^{-2}$ ). The OCP was estimated to be $0.68 \mathrm{~V}$ for RU and $0.61 \mathrm{~V}$ for $\mathrm{WW}$ reactors, based on the $\mathrm{Y}$ intercepts of the polarization curves [42].

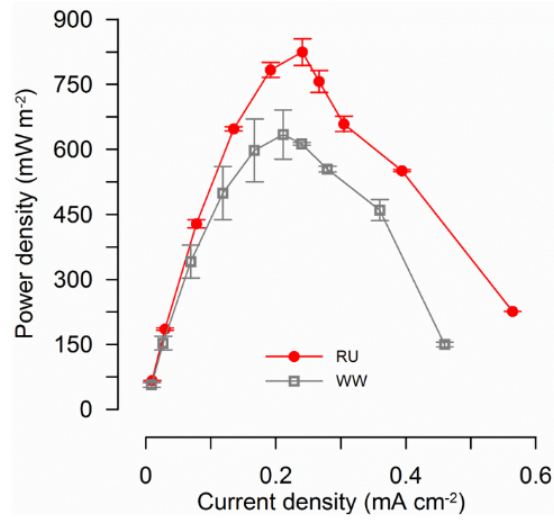

(a)

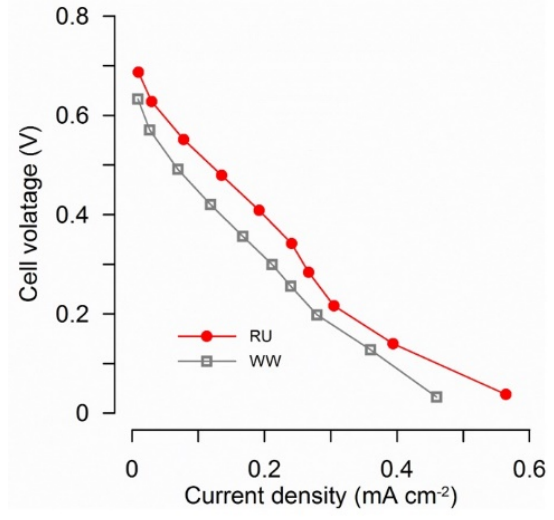

(b)

Figure 2. Polarization results for two batch cycles in duplicate reactors for each condition (during the test, external resistance was changed from $10 \Omega$ to $40 \mathrm{k} \Omega$ ). (a) Rumen reactors showed higher power production than other conditions. (b) Polarization curves for the two tested conditions showed a reduction in activation losses for rumen reactors, observed by a decrease in the slope at low current densities. RU: rumen plus wastewater; WW: wastewater.

Increases in cell voltage by adding a rumen inoculum were due to the cathodic potential. The anodic potential measurements did not show significant differences between the two inocula (Figure 3). During each cycle, the air-cathode potentials in the rumen systems ranged from about $0.12 \mathrm{~V}$ to $0.26 \mathrm{~V}$ (vs. $\mathrm{Ag} / \mathrm{AgCl}$, throughout), while in the $\mathrm{WW}$ systems, the cathode potentials were between $0.03 \mathrm{~V}$ and $0.16 \mathrm{~V}$.

Previous rumen-MFC studies conducted using cellulose as electron donor [14,16] show the presence of electrochemically active rumen bacteria. Using cyclic voltammetry (CV), Zang et al. [16] demonstrated that the electron transfer used by bacteria in an MFC inoculated with rumen fluid and fed with an aquatic plant rich in cellulose (canna) as electron donor was mainly through electron shuttles produced in canna degradation. Increases in voltage observed in this previous study were in the range of days [16], suggesting the occurrence of an indirect electron transfer mechanism. On the other hand, Kiely et al. [25] reported voltage production in about 20 min after medium replacement, suggesting direct electron transfer by bacteria attached to the electrode and no mediators involved in power production. The swift increases in cell potential observed in the present study (Figure 1), and no reductive peaks detected by CV (data not shown), suggest that direct electron transfer was the main mechanism controlling the observed differences in cathode performance. As mentioned earlier, before the MFC inoculation, the rumen fluid was enriched for two weeks in a flask using $\mathrm{H}_{2(\mathrm{~g})}$ and fumarate as electron donor and acceptor, respectively. Under these conditions, EAB, as Geobacter sulfurreducens, may have grown at the cathode, using the electrode instead of hydrogen gas as electron donor [43], enhancing electron flow and current. With this mechanism, microbial activity at the cathode could reduce activation losses and increase power production. 

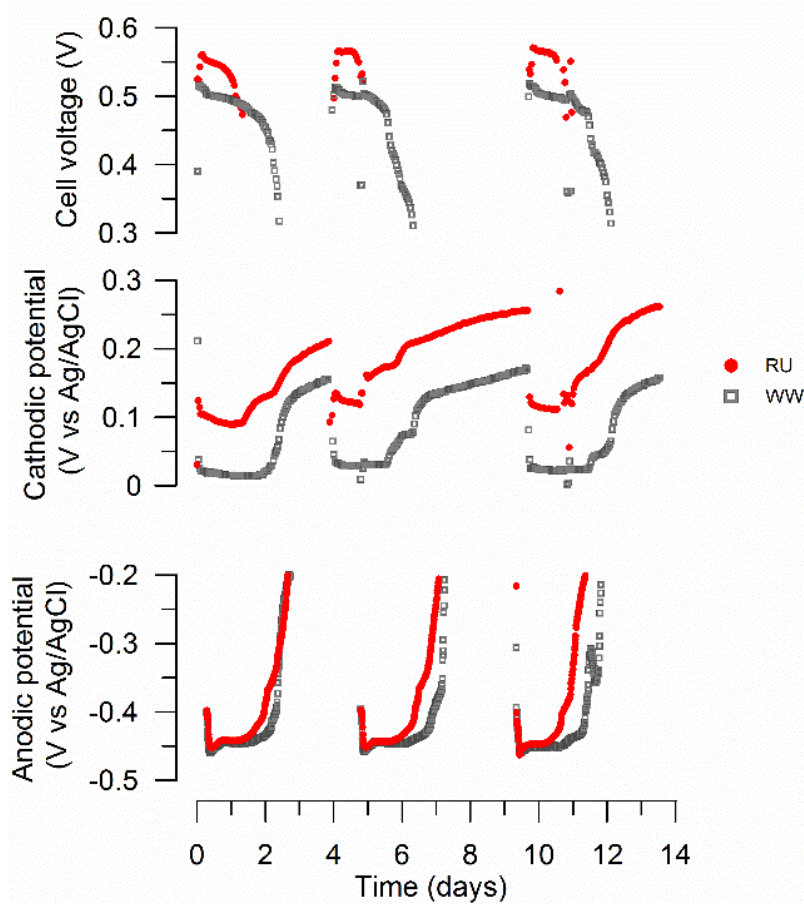

Figure 3. Differences in cathodic potential explain improvements in cell performance in rumen reactors. Cell and cathodic potential for cycles 13, 14, and 15. Anodic potential for cycles 11, 12, and 13. RU: rumen plus wastewater; WW: wastewater. The reactors were connected to external resistance of $1 \mathrm{k} \Omega$.

The thickness of these formed air-cathode biofilms was approximately $2 \mathrm{~mm}$ for RU and $1 \mathrm{~mm}$ for WW (Figure 4). Although the thickness of the RU cathodic biofilm was twice that of the WW cathodic biofilm, the rumen-inoculated systems showed higher cathodic potential and electrochemical activity (presented in the next section). Differences in RU and WW MFC performance suggest that the rumen inoculum yielded cathodic biofilm with increased substrate utilization (i.e., organics removal) and enhanced electron transfer by EAB. Similarly, Chung et al. [44] observed a gradual increase in power density while the biofilm was developed, and a decrease in power when it was removed. This suggests that the cathodic rumen biofilm could facilitate cathodic reactions, resulting in better reactor performance.
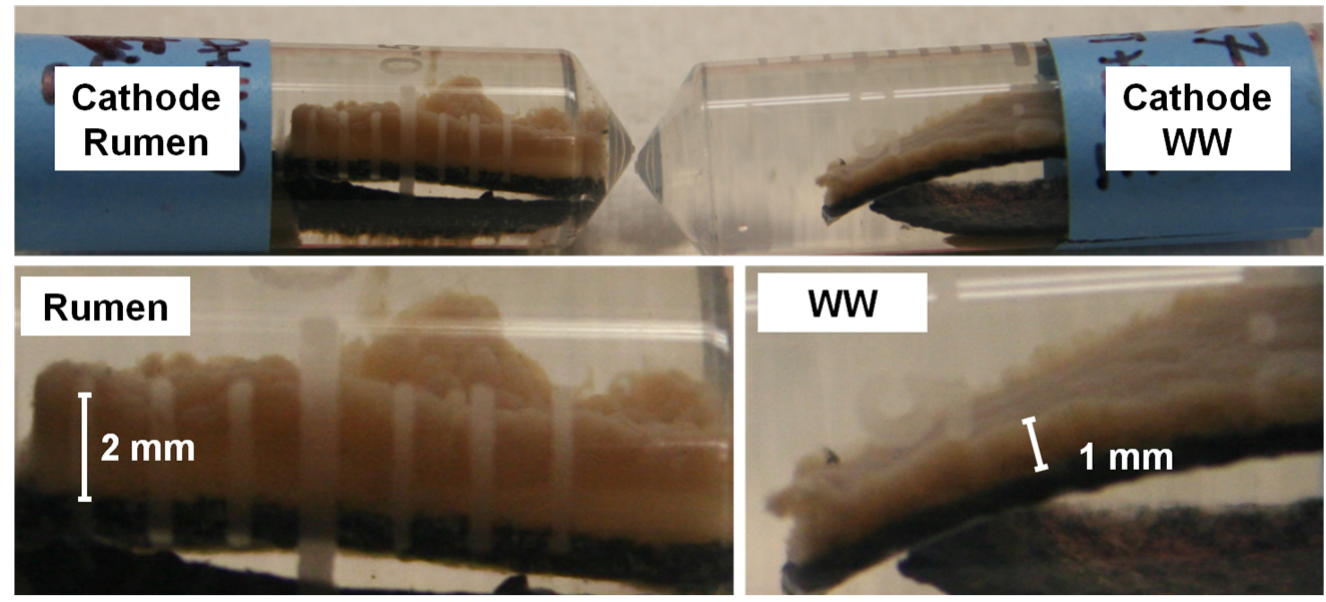

Figure 4. Photographs of biofilm formed on air-cathodes after over 60 days of operation. Bottom panels are a magnification of the top panel (WW: wastewater). 
Additionally, the results of microbial community analysis obtained by Kiely et al. [25] in a study of cathode performance in MFCs fed with different fermentation by-products and Parameswaran et al. [45] in a microbial electrolysis cell study suggest a syntrophic relationship between fermenters such as Pelobacter sp. and the known EAB Geobacter sp. in reactors fed with fermentable substrates. If present, EAB might be expected to be attached to the electrode (inner part of the biofilm), whereas aerobic and anaerobic bacteria responsible for sCOD degradation might be expected to prefer the outer part of the biofilm with higher sCOD concentrations. Differences in cell voltage between duplicate RU reactors were observed only after 44 days of operation due to a progressive cathodic biofilm detachment in one of the reactors (open diamonds in Figure 5). Interestingly, although a considerable portion of the cathodic biofilm was detached in one RU reactor and a significant decrease in CE was measured (32 to 15\%), the voltage peak did not decrease. Even more, a slight increase in power densities was observed (Figure 5), this may be because the thick biofilm impaired proton or hydroxide diffusion (Figures 4 and 6). This presumably non-electrochemically active aerobic and anaerobic consortium, formed in the outer layers of the biofilm, seemed to play an essential role in the degradation of glucose to by-products used by EAB to generate power.

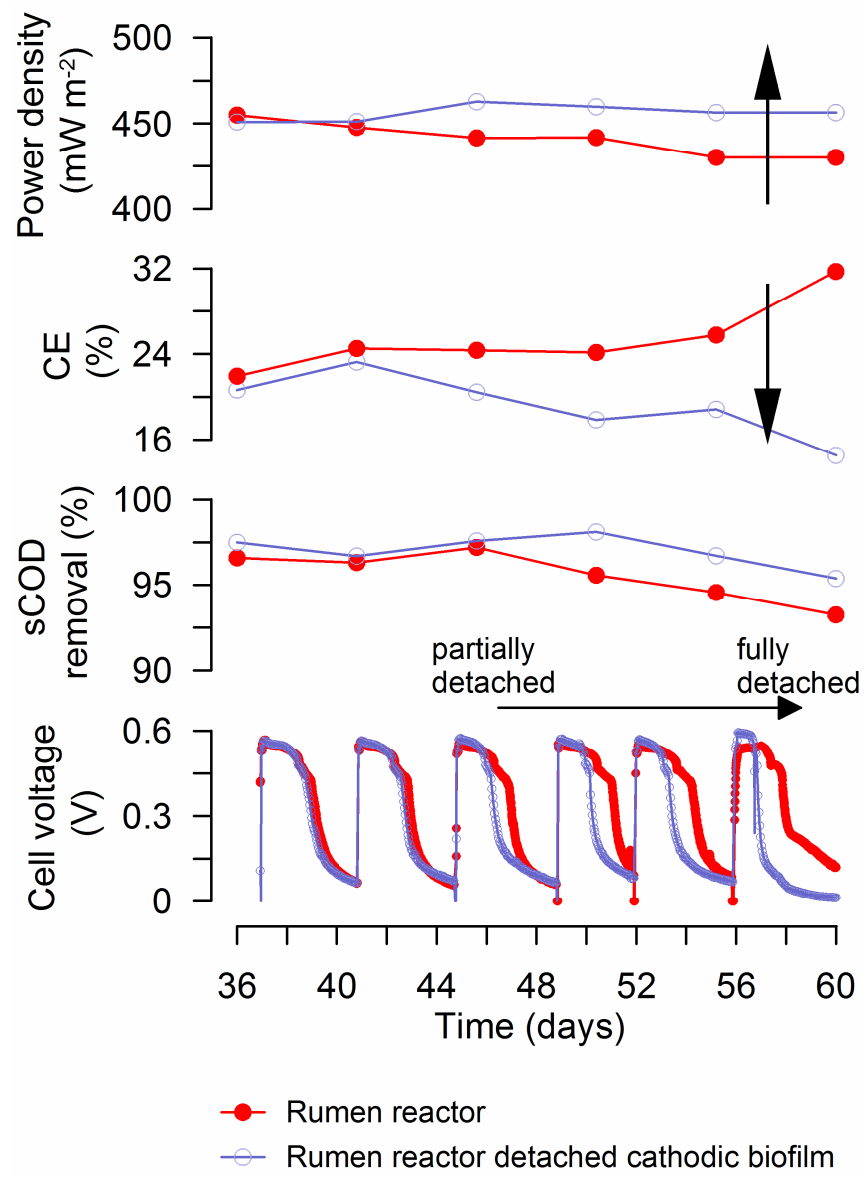

Figure 5. Effect of cathodic biofilm detachment on rumen MFC performance. Loss of the outer part of the cathodic biofilm caused decreases in cell voltages and CE, and slight increases in maximum power densities. Arrows indicate observed trends for Rumen reactors after cathode detachment. 


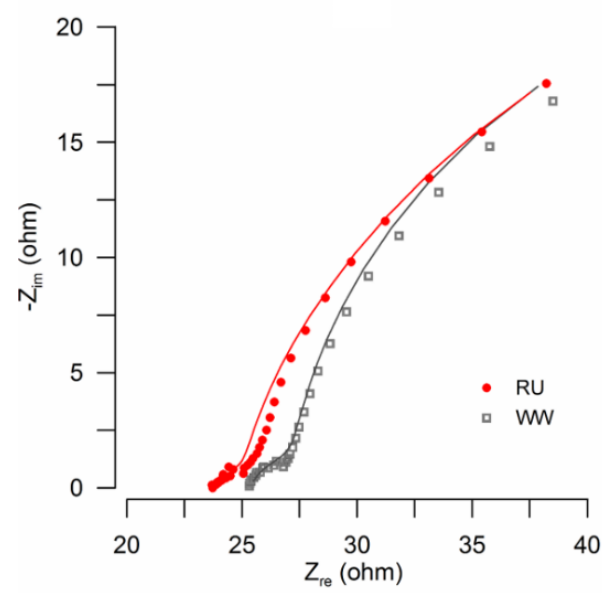

(a)

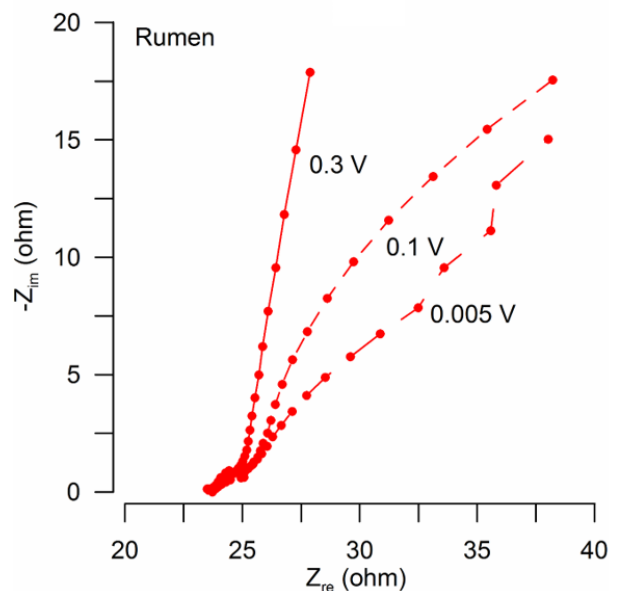

(b)

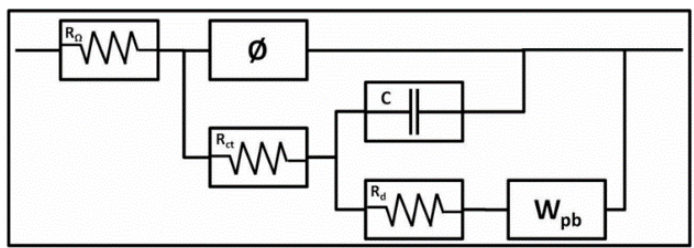

(c)

Figure 6. EIS of cathodes. (a) Nyquist plot of cathodes tested at 0.1 V. Experimental data (dots) and equivalent circuit model (lines). RU: rumen plus wastewater; WW: wastewater. (b) Nyquist plot of rumen reactor cathode poised at different potentials to show the dominance of $\mathrm{Rd}$ in the impedance. (c) The equivalent circuit was used to fit experimental data. Ohmic resistance (R $\Omega$ ); Charge transfer resistance (Rct); Diffusion resistance (Rd); Constant phase element (Ø); Capacitor (C); and Porous bounded Warburg element (Wpb).

\subsection{Analysis of Electrochemical Impedances}

EIS was performed on anodes and cathodes to quantify and characterize differences in the internal resistance of MFC reactors, with particular interest in the electron transfer resistance in cathodes enriched with the rumen inoculum. EIS analysis of the brush anodes tested at OCP showed ohmic resistances of $16 \Omega$ and $6 \Omega$ for RU and WW, respectively. This might explain the observed slight differences in anodic potentials between these systems (Figure 3). To account for the role of the rumen bio-cathode on power production increases, cathodic EIS was performed at a poised potential of $0.1 \mathrm{~V}$, estimated as the operational cathodic potential at a high current (Figure 3). EIS data were analyzed by fitting an equivalent circuit model (Figure 6 ) that included ohmic $\left(R_{\Omega}\right)$, charge transfer $\left(R_{c t}\right)$, and diffusion resistance $\left(R_{d}\right)$ based on a constant phase element (CPE) model with a double layer charging feature of porous electrodes [46], in this case, the electrochemical properties of the biocathode. To account for mass transfer, the second arc was modeled by adding a capacitor $(C)$ and a porous bounded Warburg $\left(W_{\mathrm{pb}}\right)$ element [47]. The equivalent circuit used was an adaptation of a bioanode model previously used by Jung et al. (2011) [48]. Data were successfully fitted, obtaining goodness of fit (expressed by $x^{2}$ ) from $10^{-5}$ to $10^{-3}$ [49] (Table 2). 
Table 2. Values of ohmic $\left(R_{o h m}\right)$, charge transfer $\left(R_{c t}\right)$, and diffusion $\left(R_{d}\right)$ resistance calculated by fitting experimental data with an equivalent circuit using $\chi^{2}$-minimization.

\begin{tabular}{ccc}
\hline Parameter & Rumen & WW \\
\hline $\mathrm{R}_{\mathrm{ohm}}(\Omega)$ & 23.9 & 25.3 \\
$\mathrm{R}_{\mathrm{ct}}(\Omega)$ & 3.6 & 4.1 \\
$\mathrm{R}_{\mathrm{d}}(\Omega)$ & 69.2 & 79.5 \\
Goodness $\left(\chi^{2}\right)$ & $1.77 \times 10^{-4}$ & $2.00 \times 10^{-4}$ \\
\hline
\end{tabular}

Based on the equivalent circuit analysis, rumen reactors had lower $R_{\Omega}$ and $R_{c t}$ than the wastewater inoculum. Additionally, as expected due to the high thickness of cathodic biofilms (Figure 5), for both conditions $R_{d}$ was a dominant factor of the internal resistance due to cathodic biofilm development and the resultant effect on the transport of protons in solution. Interestingly, even though the RU cathode was thicker than the WW cathode, $R_{d}$ values were slightly lower for the rumen reactor. At high potential, diffusion resistance dominated the overall impedance. Figure $6 \mathrm{~b}$ shows a Nyquist plot of the RU cathode poised at three different potentials $(0.005 \mathrm{~V}, 0.1 \mathrm{~V}$, and $0.3 \mathrm{~V})$, showing the dominance of $R_{d}$ over the impedance. Thus, results of EIS analysis suggested that increases in power production by the rumen inoculum were related to decreases in charge transfer resistance, potentially due to extracellular electron transfer improvement and diffusion resistance. In an electrochemical study of fuel cell cathodes, Springer et al. [50] reported that impedance arcs increased as the overpotential increased due to the conductivity and mass transport limitation within the catalyst layer [50]. Our results (Figure 6b) showed that for increasing overpotential, $R_{\Omega}$ and $R_{c t}$ did not significantly change, but $R_{d}$ progressively became the dominant factor of the internal resistance due to biofilm development.

\subsection{Bacterial Community Analysis}

The dominant anodic community structures were maintained for the RU and WW reactors (Figure 7a), consistent with the nearly identical anodic potentials recorded during operation (Figure 3). Anodic biofilms were dominated by Firmicutes ( $\mathrm{RU}=15 \% ; \mathrm{WW}=13 \%)$, Gammaproteobacteria (RU $=38 \% ; \mathrm{WW}=30 \%)$, and Deltaproteobacteria $(\mathrm{RU}=21 \% ; \mathrm{WW}=28 \%)$. This latter class was predominantly Geobacter spp. ( $R U=21 \%$; $W W=28 \%)$, and there was no significant relative abundance difference of this known electrochemically active group due to inoculation with the rumen enrichment. Previous community characterization in a rumen-MFC study [14] did not report Geobacter spp. as members of the anodic community. Hence, Geobacter spp. may have been added to the system by the wastewater inoculum.

On the other hand, the pyrosequencing data showed differences in the cathodic biofilm compositions between the RU and WW systems (Figure 7b). The most notable difference in the cathodic communities due to rumen enrichment was the decrease in Paracoccus spp. $(\mathrm{RU}<2 \% ; \mathrm{WW}=15 \%)$ and the increases in Azoarcus spp. $(\mathrm{RU}=26 \% ; \mathrm{WW}=2 \%)$ and Victivallis spp. (RU $=12 \%$; WW $=7 \%$ ) (Figure $7 \mathrm{~b}$ ). The decrease of Paracoccus spp. in the reactor inoculated with rumen could have a positive effect on performance. Previous studies had reported electrochemical activity by some species of Paracoccus [51,52]. However, in the presence of oxygen and nitrate, Paracoccus spp. decrease the availability of compounds used by anodic EAB, negatively affecting the power generation [36]. Observed increases in Azoarcus spp. and Victivallis spp. relative percentages due to the rumen inoculum could be associated with the observed improvements in substrate degradation (Table 1) and cathode performance (Figure 3 and Table 2). Several studies have reported Azoarcus spp. as members of electrode (anode or cathode) microbial communities [6,37,53,54]; however, there are no detailed reports about the electrochemical activity of this group. The second group that showed a significant shift in relative abundance was Victivallis spp. (phylum Lentisphaerae). Victivallis vadensis has been identified in cow rumen fluids [55] as well as in human gastrointestinal tracts and feces [56]. Recently, V. vadensis was identified as a member of an anodic community in a single-chamber MFC [7] and in an anaerobic fluidized bed MFC system [57], suggesting a possible role in electricity production. However, to 
the best of our knowledge, the electrochemical activity of Victivallis spp. has not been reported. $V$. vadensis, a Gram-negative, non-motile, strictly anaerobic bacterium is capable of growth on a range of sugars [56], similar to Azoarcus spp, that have been associated with the degradation of various organic compounds using nitrate as an electron acceptor [54]. Hence, the increase in percentages of Azoarcus and Victivallis spp. that impart high diversity for substrate degradation and electron acceptors other than oxygen, together with the significant increase in the cathodic biofilm thickness (Figure 4), suggests that the rumen enrichment could result in better substrate utilization and changes in biological oxygen consumption at the cathode surface.

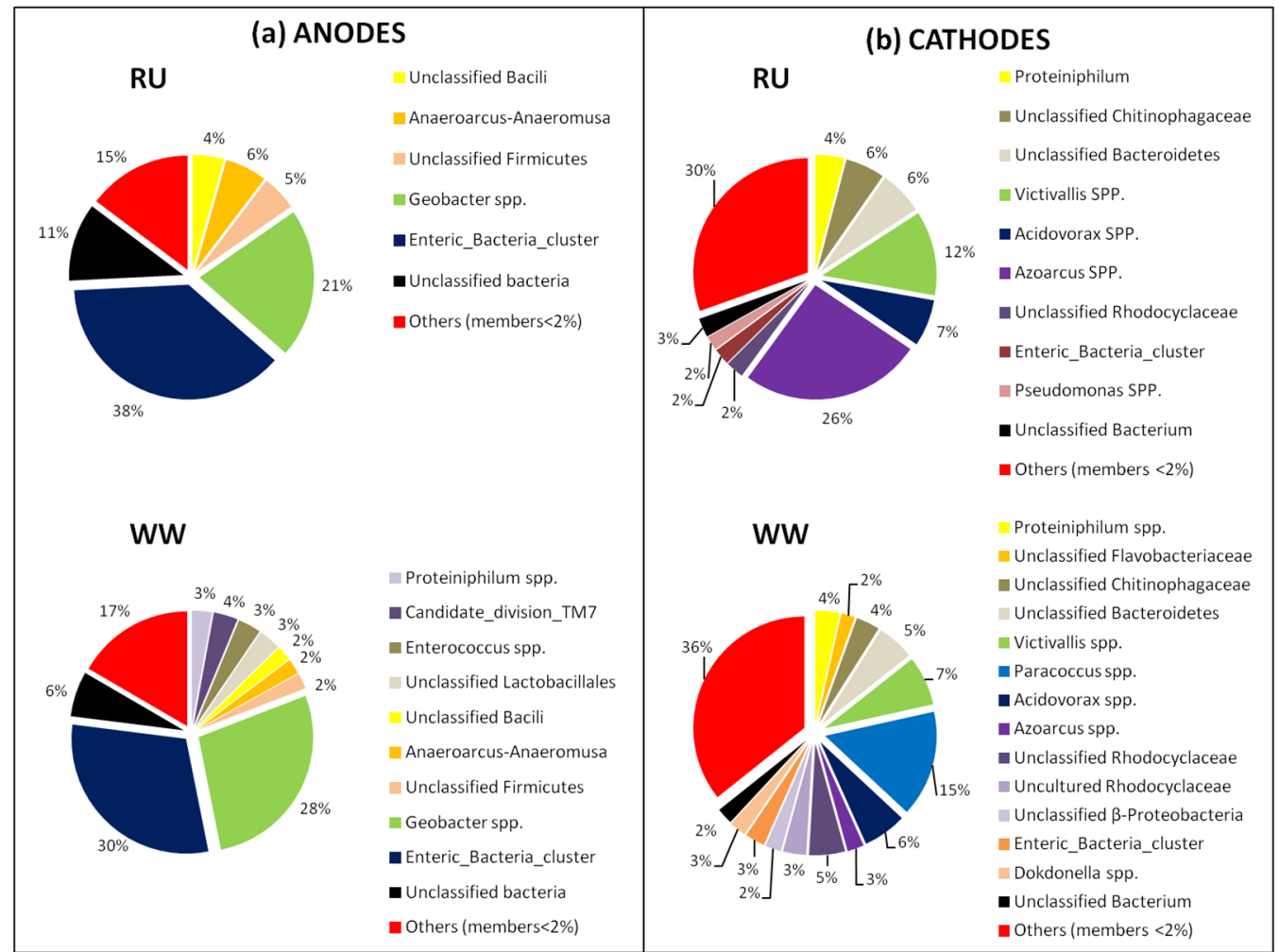

Figure 7. Genus-level community distribution of anodes (a) and cathodes (b) of rumen (RU) reactors and wastewater $(\mathrm{WW})$.

Since the rumen fluid was pre-enriched using fumarate as electron acceptor, it was used to test its effects on performance and microbial community distribution. The low percentage of Paracoccus spp. observed in Figure 7 for the rumen cathodic biofilm was also observed for rumen reactors amended with fumarate (Figure S1). However, supplementary results show a shift in the frequency of Victivallis spp. (from 12 to 20\%) and Azoarcus spp. (from 26 to 10\%) for rumen MFCs operated with fumarate (Figure S1). The effect of fumarate in performance was observed as a decrease in the maximum power density from $824.5 \mathrm{mWm}^{-2}$ exhibited for rumen reactors to $670.3 \mathrm{mWm}^{-2}$ due to fumarate addition, decreasing to the level of the WW reactors (Figure S2).

Additionally, results show a decrease in cell voltage after fumarate addition (Figure S3). These results suggest that fumarate acts as competing electron acceptor, which is concordant with dates reported by Kim and Lee, who showed that G. sulfurreducens grows using fumarate as electron acceptor [58]. However, these are contrary to what was observed by Zhang et al. in a pure culture of Shewanella oneidensis MR-1, where addition of fumarate to the medium produces an increase in power density, due to fumarate could decrease riboflavin concentration promoting direct electron transfer [59].

Finally, pyrosequencing also revealed changes in cathodic bacterial communities due to rumen enrichment of minor members (denoted as others in Figure 7), including genera 
that contain known EAB (e.g., Geobacter, Desulfobulbus, and Pseudomonas) and uncultured and unclassified bacteria that may also be playing a role on cathode oxidation. Pseudomonas is known to exchange electrons directly with an anode and cathode, which could affect the performance of the reactor [60,61]. Su et al. [61] observed denitrification and dissimilatory nitrate reduction to ammonium by Pseudomonas alcaliphila with an electrode as a sole electron donor. Additionally, Cournet et al. [60] reported the electrochemical reduction of oxygen by Pseudomonas aeruginosa and Pseudomonas fluorescens.

Thus, while the development of a thicker cathodic biofilm was expected to result in higher CE based on the results of other studies, our results also show that it does not necessarily involve decreases in power densities. The presence of syntrophic relationships for substrate degradation and EAB seems to be a key factor to enhance cathodic oxidation, even in the presence of high mass transfer resistance and limitation of proton diffusion from the bulk solution to the catalyst layer due to thicker biofilm formation.

\section{Conclusions}

This study explored, for the first time, the effect of a rumen fluid inoculum on the composition of anodic and cathodic microbial communities in single-chamber air-cathode MFC reactors. The results show that the rumen fluid inoculum increased SCOD removal and power production in the tested MFC reactors. This enhancement was due to the resulted cathodic biofilm, explained by a shift in its microbial composition. Results show an increase in percentages of Azoarcus and Victivallis species, together with a small occurrence of known $E A B$, at the rumen inoculated cathode. This research allows us to focus further attention on the effect of new sources of inoculum, such as rumen fluid, on cathodic microbial communities and identify novel bacterial groups that could potentially enhance cathode performance and substrate degradation. Additional efforts are required to investigate the role of Azoarcus and Victivallis in the cathodic biofilm.

Supplementary Materials: The following supporting information can be downloaded at: https: / / www.mdpi.com/article/10.3390/ma15010379/s1, Figure S1: Genus-level community distribution of cathodes of rumen (RU), rumen plus fumarate $(R F)$ and wastewater (WW) reactors, Figure S2: Power density curves of MFC reactors, Figure S3: MFC reactor inoculated with rumen enrichment and amended with $60 \mathrm{mgL}^{-1}$ of fumarate (additional to the $1 \mathrm{gL}^{-1}$ of glucose) for each batch-cycle, during 60 days of operation.

Author Contributions: Conceptualization, I.T.V. and J.M.R.; methodology, I.T.V. and J.M.R.; formal analysis, I.T.V., N.T., and J.M.R.; investigation, I.T.V., N.T., and J.M.R.; resources, J.M.R.; writingoriginal draft preparation, I.T.V.; writing-review and editing, I.T.V., N.T. and J.M.R.; supervision, J.M.R.; project administration, J.M.R.; funding acquisition, J.M.R. All authors have read and agreed to the published version of the manuscript.

Funding: This research was supported by Award KUS-I1-003-13 from the King Abdullah University of Science and Technology (KAUST) and FONDECYT project 1201134 under the Centro de Desarrollo Urbano Sustentable (CEDEUS) CONICYT/FONDAP /15110020.

Institutional Review Board Statement: Not applicable.

Informed Consent Statement: Not applicable.

Data Availability Statement: Data sharing is not applicable to this article.

Acknowledgments: The authors would like to thank Istvan U. Albert for support in sequence analysis, Alexander N. Hristov and his research group for providing us the rumen sample, and Deb Grove at the Penn State Genomics Core Facility (University Park, PA, USA, 16801) for DNA pyrosequencing.

Conflicts of Interest: The authors declare no conflict of interest. 


\section{References}

1. Munoz-Cupa, C.; Hu, Y.; Xu, C.; Bassi, A. An overview of microbial fuel cell usage in wastewater treatment, resource recovery and energy production. Sci. Total Environ. 2020, 754, 142429. [CrossRef] [PubMed]

2. Jatoi, A.S.; Akhter, F.; Mazari, S.A.; Sabzoi, N.; Aziz, S.; Soomro, S.A.; Mubarak, N.M.; Baloch, H.; Memon, A.Q.; Ahmed, S. Advanced microbial fuel cell for waste water treatment-A review. Environ. Sci. Pollut. Res. 2020, 28, 5005-5019. [CrossRef]

3. Flimban, S.G.; Ismail, I.M.; Kim, T.; Oh, S.E. Overview of recent advancements in the microbial fuel cell from fundamentals to applications: Design, major elements, and scalability. Energies 2019, 12, 3390. [CrossRef]

4. Slate, A.J.; Whitehead, K.A.; Brownson, D.; Banks, C.E. Microbial fuel cells: An overview of current technology. Renew. Sustain. Energy Rev. 2018, 101, 60-81. [CrossRef]

5. Dopson, M.; Ni, G.; Sleutels, T.H. Possibilities for extremophilic microorganisms in microbial electrochemical systems. FEMS Microbiol. Rev. 2015, 40, 164-181. [CrossRef] [PubMed]

6. Chen, J.; Hu, Y.; Zhang, L.; Huang, W.; Sun, J. Bacterial community shift and improved performance induced by in situ preparing dual graphene modified bioelectrode in microbial fuel cell. Bioresour. Technol. 2017, 238, 273-280. [CrossRef] [PubMed]

7. Yang, N.; Ren, Y.; Li, X.; Wang, X. Effect of short-term alkaline intervention on the performance of buffer-free single-chamber microbial fuel cell. Bioelectrochemistry 2017, 115, 41-46. [CrossRef] [PubMed]

8. Ishii, S.; Suzuki, S.; Norden-Krichmar, T.M.; Phan, T.; Wanger, G.; Nealson, K.H.; Sekiguchi, Y.; Gorby, Y.A.; Bretschger, O. Microbial population and functional dynamics associated with surface potential and carbon metabolism. ISME J. 2013, 8, 963-978. [CrossRef] [PubMed]

9. Miceli, J.F.; Parameswaran, P.; Kang, D.-W.; Krajmalnik-Brown, R.; Torres, C.I. Enrichment and Analysis of Anode-Respiring Bacteria from Diverse Anaerobic Inocula. Environ. Sci. Technol. 2012, 46, 10349-10355. [CrossRef] [PubMed]

10. Kouzuma, A.; Kasai, T.; Nakagawa, G.; Yamamuro, A.; Abe, T.; Watanabe, K. Comparative Metagenomics of Anode-Associated Microbiomes Developed in Rice Paddy-Field Microbial Fuel Cells. PLoS ONE 2013, 8, e77443. [CrossRef]

11. Dunaj, S.; Vallino, J.; Hines, M.E.; Gay, M.; Kobyljanec, C.; Rooney-Varga, J.N. Relationships between Soil Organic Matter, Nutrients, Bacterial Community Structure, And the Performance of Microbial Fuel Cells. Environ. Sci. Technol. 2012, 46, 1914-1922. [CrossRef] [PubMed]

12. Chin-Tsan, W.; Che-Ming, Y.; Zih-Sheng, C.; Yao-Cheng, L. Performance of straw-fed microbial fuel cells with mixed rumen microorganisms by using different catholytes. Biomass-Bioenergy 2013, 59, 412-417. [CrossRef]

13. Chung, R.; Kang, E.Y.; Shin, Y.J.; Park, J.J.; Park, P.S.; Han, C.H.; Kim, B.; Moon, S.I.; Park, J.; Chung, P.S. Development of a Consolidated Anaerobic Digester and Microbial Fuel Cell to Produce Biomethane and Electricity from Cellulosic Biomass Using Bovine Rumen Microorganisms. J. Sustain. Bioenergy Syst. 2019, 9, 17-28. [CrossRef]

14. Rismani-Yazdi, H.; Christy, A.D.; Dehority, B.A.; Morrison, M.; Yu, Z.; Tuovinen, O.H. Electricity generation from cellulose by rumen microorganisms in microbial fuel cells. Biotechnol. Bioeng. 2007, 97, 1398-1407. [CrossRef] [PubMed]

15. Wang, Z.; Hong, Q.; Shu, M.; Chen, Y.; Dong, L.; Ming, Y. Rumen bacteria convert cellulose into electricity in two-chamber microbial fuel cell. J. Chem. Pharm. Res. 2014, 6, 727-732.

16. Zang, G.-L.; Sheng, G.-P.; Tong, Z.-H.; Liu, X.-W.; Teng, S.-X.; Li, W.-W.; Yu, H.-Q. Direct Electricity Recovery from Canna indica by an Air-Cathode Microbial Fuel Cell Inoculated with Rumen Microorganisms. Environ. Sci. Technol. 2010, 44, 2715-2720. [CrossRef]

17. Rousseau, R.; Dominguez-Benetton, X.; Délia, M.-L.; Bergel, A. Microbial bioanodes with high salinity tolerance for microbial fuel cells and microbial electrolysis cells. Electrochem. Commun. 2013, 33, 1-4. [CrossRef]

18. Pierra, M.; Carmona-Martínez, A.A.; Trably, E.; Godon, J.-J.; Bernet, N. Specific and efficient electrochemical selection of Geoalkalibacter subterraneus and Desulfuromonas acetoxidans in high current-producing biofilms. Bioelectrochemistry 2015, 106, 221-225. [CrossRef]

19. Salvin, P.; Roos, C.; Robert, F. Tropical mangrove sediments as a natural inoculum for efficient electroactive biofilms. Bioresour. Technol. 2012, 120, 45-51. [CrossRef]

20. Leiva-Aravena, E.; Leiva, E.; Zamorano, V.; Rojas, C.; Regan, J.M.; Vargas, I.T. Organotrophic acid-tolerant microorganisms enriched from an acid mine drainage affected environment as inoculum for microbial fuel cells. Sci. Total Environ. 2019, 678, 639-646. [CrossRef] [PubMed]

21. Li, M.; Zhou, M.; Tian, X.; Tan, C.; McDaniel, C.T.; Hassett, D.J.; Gu, T. Microbial fuel cell (MFC) power performance improvement through enhanced microbial electrogenicity. Biotechnol. Adv. 2018, 36, 1316-1327. [CrossRef]

22. Kumar, R.; Singh, L.; Zularisam, A.W.; Hai, F. Microbial fuel cell is emerging as a versatile technology: A review on its possible applications, challenges and strategies to improve the performances. Int. J. Energy Res. 2017, 42, 369-394. [CrossRef]

23. Qu, Y.; Feng, Y.; Wang, X.; Logan, B.E. Use of a Coculture to Enable Current Production by Geobacter sulfurreducens. Appl. Environ. Microbiol. 2012, 78, 3484-3487. [CrossRef] [PubMed]

24. Al Lawati, M.J.; Jafary, T.; Baawain, M.S.; Al-Mamun, A. A mini review on biofouling on air cathode of single chamber microbial fuel cell; prevention and mitigation strategies. Biocatal. Agric. Biotechnol. 2019, 22, 101370. [CrossRef]

25. Kiely, P.D.; Rader, G.; Regan, J.M.; Logan, B.E. Long-term cathode performance and the microbial communities that develop in microbial fuel cells fed different fermentation endproducts. Bioresour. Technol. 2011, 102, 361-366. [CrossRef] [PubMed]

26. Yang, W.; Rossi, R.; Tian, Y.; Kim, K.-Y.; Logan, B.E. Mitigating external and internal cathode fouling using a polymer bonded separator in microbial fuel cells. Bioresour. Technol. 2017, 249, 1080-1084. [CrossRef] [PubMed]

27. Nagaraja, T.G. Microbiology of the rumen. In Rumenology; Springer: Basel, Switzerland, 2016. 
28. Gregoire, K.; Becker, J. Design and characterization of a microbial fuel cell for the conversion of a lignocellulosic crop residue to electricity. Bioresour. Technol. 2012, 119, 208-215. [CrossRef]

29. Tsan, W.C.; Ming, Y.C.; Sheng, C.Z.; Shuai, T. Effect of biometric flow channel on the power generation at different Reynolds numbers in the single chamber of rumen microbial fuel cells (RMFCs). Int. J. Hydrog. Energy 2011, 36, 9242-9251. [CrossRef]

30. Wang, C.T.; Yang, C.M.; Chen, Z.S. Method of Correlation Among Fermentation Acids and Reducing Power from Substrate Degradation Applied to Investigate the Electrochemistry Process of Rumen Microbial Fuel Cells (RMFCs). J. Chin. Soc. Mech. Eng. 2012, 33, 249-255.

31. Wang, C.-T.; Yang, C.-M.J.; Chen, Z.-S. Rumen microbial volatile fatty acids in relation to oxidation reduction potential and electricity generation from straw in microbial fuel cells. Biomass Bioenergy 2012, 37, 318-329. [CrossRef]

32. Chang, S.; Shin, M.J.; Kim, Y.; Jang, S.J.; Moon, S.I.; Jeong, S.; Shim, R.; Shen, F.; Kang, S.; Chung, P.S. Influence of Red Pepper (Capsicum annuum) Addition on Bioenergy Production in Microbial Fuel Cells. J. Sustain. Bioenergy Syst. 2019, 9, 179-188. [CrossRef]

33. Feng, Y.; Yang, Q.; Wang, X.; Logan, B.E. Treatment of carbon fiber brush anodes for improving power generation in air-cathode microbial fuel cells. J. Power Sources 2010, 195, 1841-1844. [CrossRef]

34. Cusick, R.D.; Kiely, P.D.; Logan, B.E. A monetary comparison of energy recovered from microbial fuel cells and microbial electrolysis cells fed winery or domestic wastewaters. Int. J. Hydrog. Energy 2010, 35, 8855-8861. [CrossRef]

35. Ueki, T.; Lovley, D.R. Genome-wide gene regulation of biosynthesis and energy generation by a novel transcriptional repressor in Geobacter species. Nucleic Acids Res. 2009, 38, 810-821. [CrossRef]

36. Kiely, P.D.; Call, D.F.; Yates, M.D.; Regan, J.M.; Logan, B.E. Anodic biofilms in microbial fuel cells harbor low numbers of higher-power-producing bacteria than abundant genera. Appl. Microbiol. Biotechnol. 2010, 88, 371-380. [CrossRef] [PubMed]

37. Kim, J.R.; Jung, S.; Regan, J.M.; Logan, B.E. Electricity generation and microbial community analysis of alcohol powered microbial fuel cells. Bioresour. Technol. 2007, 98, 2568-2577. [CrossRef] [PubMed]

38. Kiely, P.D.; Cusick, R.; Call, D.; Selembo, P.A.; Regan, J.M.; Logan, B.E. Anode microbial communities produced by changing from microbial fuel cell to microbial electrolysis cell operation using two different wastewaters. Bioresour. Technol. 2011, 102, 388-394. [CrossRef] [PubMed]

39. Vargas, I.T.; Albert, I.U.; Regan, J.M. Spatial distribution of bacterial communities on volumetric and planar anodes in singlechamber air-cathode microbial fuel cells. Biotechnol. Bioeng. 2013, 110, 3059-3062. [CrossRef] [PubMed]

40. Pruesse, E.; Quast, C.; Knittel, K.; Fuchs, B.M.; Ludwig, W.; Peplies, J.; Glöckner, F.O. SILVA: A comprehensive online resource for quality checked and aligned ribosomal RNA sequence data compatible with ARB. Nucleic Acids Res. 2007, 35, 7188-7196. [CrossRef] [PubMed]

41. Schloss, P.D.; Westcott, S.L.; Ryabin, T.; Hall, J.R.; Hartmann, M.; Hollister, E.B.; Lesniewski, R.A.; Oakley, B.B.; Parks, D.H.; Robinson, C.J.; et al. Introducing mothur: Open-Source, Platform-Independent, Community-Supported Software for Describing and Comparing Microbial Communities. Appl. Environ. Microbiol. 2009, 75, 7537-7541. [CrossRef] [PubMed]

42. Lawson, K.; Rossi, R.; Regan, J.M.; Logan, B.E. Impact of cathodic electron acceptor on microbial fuel cell internal resistance. Bioresour. Technol. 2020, 316, 123919. [CrossRef]

43. Rosenbaum, M.; Aulenta, F.; Villano, M.; Angenent, L. Cathodes as electron donors for microbial metabolism: Which extracellular electron transfer mechanisms are involved? Bioresour. Technol. 2011, 102, 324-333. [CrossRef] [PubMed]

44. Chung, K.; Fujiki, I.; Okabe, S. Effect of formation of biofilms and chemical scale on the cathode electrode on the performance of a continuous two-chamber microbial fuel cell. Bioresour. Technol. 2011, 102, 355-360. [CrossRef]

45. Parameswaran, P.; Torres, C.I.; Lee, H.-S.; Krajmalnik-Brown, R.; Rittmann, B.E. Syntrophic interactions among anode respiring bacteria (ARB) and Non-ARB in a biofilm anode: Electron balances. Biotechnol. Bioeng. 2009, 103, 513-523. [CrossRef] [PubMed]

46. You, S.-J.; Ren, N.-Q.; Zhao, Q.-L.; Wang, J.-Y.; Yang, F.-L. Power Generation and Electrochemical Analysis of Biocathode Microbial Fuel Cell Using Graphite Fibre Brush as Cathode Material. Fuel Cells 2009, 9, 588-596. [CrossRef]

47. Kim, J.R.; Premier, G.C.; Hawkes, F.R.; Dinsdale, R.M.; Guwy, A.J. Development of a tubular microbial fuel cell (MFC) employing a membrane electrode assembly cathode. J. Power Sources 2009, 187, 393-399. [CrossRef]

48. Jung, S.; Mench, M.M.; Regan, J.M. Impedance Characteristics and Polarization Behavior of a Microbial Fuel Cell in Response to Short-Term Changes in Medium pH. Environ. Sci. Technol. 2011, 45, 9069-9074. [CrossRef] [PubMed]

49. Taylor, J. An Introduction to Error Analysis: The Study of Uncertainties in Physical Measurements; University Science Books: Sausalito, CA, USA, 1997; p. 268

50. Springer, T.E.; Zawodzinski, T.A.; Wilson, M.S.; Gottesfeld, S. Characterization of Polymer Electrolyte Fuel Cells Using AC Impedance Spectroscopy. J. Electrochem. Soc. 1996, 143, 587-599. [CrossRef]

51. Jothinathan, D.; Wilson, R.T. Comparative analysis of power production of pure, coculture, and mixed culture in a microbial fuel cell. Energy Sources Part A Recover. Util. Environ. Eff. 2017, 39, 520-527. [CrossRef]

52. Xie, D.; Yu, H.; Li, C.; Ren, Y.; Wei, C.; Feng, C. Competitive microbial reduction of perchlorate and nitrate with a cathode directly serving as the electron donor. Electrochim. Acta 2014, 133, 217-223. [CrossRef]

53. Montpart, N.; Rago, L.; Baeza, J.A.; Guisasola, A. Oxygen barrier and catalytic effect of the cathodic biofilm in single chamber microbial fuel cells. J. Chem. Technol. Biotechnol. 2018, 93, 2199-2207. [CrossRef]

54. Rago, L.; Cristiani, P.; Villa, F.; Zecchin, S.; Colombo, A.; Cavalca, L.; Schievano, A. Influences of dissolved oxygen concentration on biocathodic microbial communities in microbial fuel cells. Bioelectrochemistry 2017, 116, 39-51. [CrossRef] [PubMed] 
55. Callaway, T.R.; Dowd, S.E.; Edrington, T.S.; Anderson, R.C.; Krueger, N.; Bauer, N.; Kononoff, P.J.; Nisbet, D.J. Evaluation of bacterial diversity in the rumen and feces of cattle fed different levels of dried distillers grains plus solubles using bacterial tag-encoded FLX amplicon pyrosequencing. J. Anim. Sci. 2010, 88, 3977-3983. [CrossRef] [PubMed]

56. Zoetendal, E.G.; Plugge, C.M.; Akkermans, A.D.L.; de Vos, W.M. Victivallis vadensis gen. nov., sp. nov., a sugar-fermenting anaerobe from human faeces. Int. J. Syst. Evol. Microbiol. 2003, 53, 211-215. [CrossRef]

57. Huang, J.-S.; Guo, Y.; Yang, P.; Li, C.-M.; Gao, H.; Feng, L.; Zhang, Y. Performance evaluation and bacteria analysis of AFB-MFC enriched with high-strength synthetic wastewater. Water Sci. Technol. 2013, 69, 9-14. [CrossRef] [PubMed]

58. Kim, M.-S.; Lee, Y.-J. Optimization of culture conditions and electricity generation using Geobacter sulfurreducens in a dualchambered microbial fuel-cell. Int. J. Hydrog. Energy 2010, 35, 13028-13034. [CrossRef]

59. Zhang, P.; Liu, J.; Qu, Y.; Feng, Y. Enhanced Shewanella oneidensis MR-1 anode performance by adding fumarate in microbial fuel cell. Chem. Eng. J. 2017, 328, 697-702. [CrossRef]

60. Cournet, A.; Délia, M.-L.; Bergel, A.; Roques, C.; Bergé, M. Electrochemical reduction of oxygen catalyzed by a wide range of bacteria including Gram-positive. Electrochem. Commun. 2010, 12, 505-508. [CrossRef]

61. Su, W.; Zhang, L.; Li, D.; Zhan, G.; Qian, J.; Tao, Y. Dissimilatory nitrate reduction by Pseudomonas alcaliphila with an electrode as the sole electron donor. Biotechnol. Bioeng. 2012, 109, 2904-2910. [CrossRef] [PubMed] 